\title{
¿Quién habita las ciudades? Exclusiones, intersecciones y atravesamientos
}

\author{
Paola Bonavitta \\ Universidad Nacional de Córdoba \\ Recibido: 25 de junio del 2018 / Aprobado: 23 de agosto del 2018 \\ doi: 10.26439/limaq2019.n005.4528
}

Las ciudades posmodernas representan la lógica de lo efímero y del consumo cotidiano. Por momentos, en sus calles reina el tránsito apurado, fugaz. En otros, las heridas de la resistencia no cierran y se someten a las lógicas de quienes resisten y luchan. Son ciudades apropiadas por distintos cuerpos: autóctonos, casi locales, migrantes, cada quien habitando sus lugares y sus no lugares. ¿Qué cuerpos pueden circular en las ciudades posmodernas? ¿Qué pasa con los cuerpos que no tienen cabida en dichos territorios? La lógica urbana responde al consumo masivo. Sus calles también. La herida de la colonialidad no cierra y se remapean espacios, cuerpos y apropiaciones en cartografias imaginarias disponibles para la lectura implícita del diseño local/ regional/global.

ciudades posmodernas, consumo, colonialidad, migración, efímero

\section{Who dwells in the cities? Exclusions, intersections and crossings}

Postmodern cities represent the logic of ephemeralness and daily consumption. Sometimes streets are ruled by a hectic and fleeting traffic flow. At other times the wounds of resistance do not heal, and they submit to the logic of those who resist and fight. They are cities taken by different bodies: natives, almost local, migrants; each one dwelling in his/her places and no-places. Which bodies can move around postmodern cities? What happens to those who do not have a place in said territories? The urban logic responds to massive consumption. So do its streets. The wound of coloniality does not heal and the spaces, bodies and ownerships are remapped in imaginary cartographies available for the implicit reading of local/regional/global design.

postmodern cities, consumption, coloniality, migration, ephemeral 


\section{INTRODUCCIÓN}

La colonia dejó sus marcas a cada paso en América Latina.Y eso no solo se ve en las construcciones de época, en las callecitas de piedra o en algunos edificios gubernamentales que sobreviven con la estética colonial a lo largo y ancho de nuestra región.

La colonia dejó huellas aún más profundas, que nos han marcado y nos generan mapas mentales que dividen nuestra sociedad. La colonización estableció una diferencia entre clases, castas, razas y género, y nos convenció de que había una raza superior (la blanca) y de que había un género más fuerte (varones) y una clase social que merece privilegios. Estableció jerarquías de poder en nuestros territorios y, por ende, jerarquías de acceso y posibilidades de accesos. Los varones blancos, que constituían la clase social más favorecida, también eran los dueños de la epistemología considerada válida (la eurocéntrica) y los saberes de allí derivados, que fueron marcados como legítimos.

Ese legado aún está presente en diversas circunstancias, pues seguimos estructurando nuestro pensamiento y acción sobre la base de esos patrones de saber salpicados de privilegios. Entonces, así como vivimos en una sociedad patriarcal, sexista, clasista, eurocéntrica, racista y que prioriza la mirada de las personas adultas, habitamos ciudades que toman esas mismas características. Los entramados comunitarios se pierden en las ciudades latinoamericanas y atravesamos espacios cruzados por las lógicas capitalistas: nos rige la idea de que el tiempo vale oro, pues tiempo es dinero y transitamos las ciudades con la ligereza de quien pierde constantemente el transporte urbano. Pero también vemos al capitalismo atravesarnos de distintas formas: centros comerciales destinados a ciertas clases sociales, en barrios también privilegiados; ciudades seguras para los varones blancos de clase media e inseguras para las mujeres; ciudades pensadas para transitarlas sin hijos ni hijas, predispuestas para que las cuidadoras se queden atoradas en la periferia realizando sus tareas de cuidados y no se acerquen a los centros, donde las economías funcionan. Estas ciudades capitalistas marcan un centro y una periferia, así como ya lo habían hecho con la división del mundo.

Y ese centro y periferia están absolutamente atravesados por las clases: quienes habitan y transitan los centros son quienes tienen la capacidad 
de consumir los productos que ofrece el capitalismo. Pero también están marcados por otras categorías como la raza y el género. Las mujeres pobres de las ciudades latinoamericanas están entrampadas en la periferia, dedicadas a trabajos de cuidado. Tomar el transporte público se vuelve una odisea, y es mucho peor si el clima está lluvioso. Las esperas eternas, los transportes que no circulan por donde deben ni cuando les corresponde, los altos costos de los boletos, etcétera, dificultan los accesos. Las mujeres, con hijos e hijas, prefieren quedarse cuidándolos en los barrios. Pareciera una elección, pero no lo es: el sistema las aísla y las ciudades las separan. Movilizarse con criaturas es imposible para ellas. Quedan aisladas en los barrios, sin poder concretar trabajos o acercarse al centro de la ciudad, libradas al azar que marca la pobreza, sin poder elegir destinos. Lo mismo sucede con las personas con discapacidad. La ciudad no está pensada para las diferencias, sino para homogeneizar según lógicas dominantes.

Otras mujeres, de otras clases sociales, igualmente terminan quedando entrampadas en lujosas viviendas. Las ciudades son inseguras para ellas también: temen ser violadas, acosadas, asaltadas. Entonces, se quedan en sus lujosos hogares —asímismo periféricos - pero protegidas por personal de seguridad privada (que, a su vez, proviene de las márgenes pobres de la ciudad). Unas y otras están entrampadas. No pueden salir, no pueden moverse libremente, no circulan como quisieran. Las ciudades están hechas para los varones, pues ellos pueden transitarlas a cualquier hora con menores riesgos.

En los espacios urbanos grandes, las lógicas del cuidado comunitario van desapareciendo. Vecinos que no se conocen entre sí, desconfianza de quien está al lado, torpeza al dialogar tímidamente, sin saber con quién. El miedo se apodera de las ciudades y los vínculos se vuelven difusos y esporádicos, escasamente profundos y plagados de dudas y temores. La sensación de anomia aumenta: se pierden lazos, redes y marcos de contención.

Las mujeres son de las más desfavorecidas en este contexto, puesto que las ciudades son más inseguras para ellas. Como señaló la arquitecta Ana Falú:

Los barrios con terrenos baldíos y calles oscuras y solitarias son parte del escenario urbano poco "amigable" a las mujeres. Estamos tratando de evidenciar que el problema de la violencia en las mujeres tiene una connotación particular: las mujeres son pensadas como cuerpos para ser abusados. (Falú, 2014, p. 17) 
En las ciudades existen sectores que las mujeres no cruzamos, no transitamos, y existen horarios cuando no se circula por miedo a un ataque, al acoso o a ser violadas. La división sexual del trabajo es lo que subyace al cómo están pensadas las ciudades en su perspectiva de género. Hay sujetos omitidos en el planeamiento urbano y las mujeres somos quienes más hemos soportado el crecimiento de la pobreza.

Los espacios públicos de las ciudades siguen siendo mayoritariamente masculinos:

Uno de los factores que dificultan la "irrupción" plena de las mujeres como ciudadanas en lo público, de la apropiación de estas en las diferentes escalas de territorios, son las violencias que se ejercen contra estas en los espacios públicos, las que podrían operar a modo de mecanismo de restricción de los derechos de las mujeres a la ciudad, y de manera más amplia, a la posibilidad de efectivizar el conjunto de derechos conquistados en los ámbitos políticos, económicos, sociales. (Falú, 2014, p. 18)

Asimismo, otros de los grandes desfavorecidos de las ciudades posmodernas son las personas migrantes, sobre todo aquellas que pertenecen a países latinoamericanos, limítrofes y pobres. La marca de la diferencia se porta en los rostros, pues se visibiliza la piel morena, los rasgos indígenas o árabes, la mediana a baja estatura... esos rostros que no llevan marcas de la occidentalización son los que circulan de manera insegura en las calles latinoamericanas. Estas personas son fácilmente detenidas por la policía, cuestionadas por su situación de legalidad/ilegalidad y apresadas si no están en un sistema que, al mismo tiempo, las expulsa o las contrata informalmente; refugiadas en guetos de pobreza, separados de la idea de nación. Son quienes quedan siempre en las márgenes, señaladas constantemente por la marca de su ilegalidad.

\section{LA CIUDAD COMO UNA CONSTRUCCIÓN SOCIAL}

Reflexionar sobre la ciudad como una categoría de construcción social supone dar cuenta de las modalidades bajo las cuales esta es significada y construida por quienes la habitan. Sabemos que el $80 \%$ de la población latinoamericana habita en espacios urbanos; eso hace que sea la región más 
urbanizada del mundo, pero también la más inequitativa (Programa de las Naciones Unidas para los Asentamientos Humanos [ONU-Habitat], 2012). Recordemos, además, que en Latinoamérica dos de cada tres personas son pobres (Comisión Económica para América Latina y el Caribe [CEPAL], 2012). Entonces, pensar en las ciudades como territorios implica pensar en este cruce entre clases. Asimismo, de esos pobres, el $70 \%$ son mujeres (CEPAL, 2012); por tanto, existe una feminización de la pobreza en la región que afecta en el habitar, transitar y apropiarse de los lugares. Sumado a esto, en un plano habitacional, la cantidad y calidad de viviendas disponibles no son suficientes para garantizar condiciones mínimas a todos los hogares. La oferta de espacios públicos también es inequitativa. Los barrios periféricos o marginales cuentan con escasos espacios públicos y son de muy baja calidad. El énfasis ha estado en lograr la seguridad de la tenencia y en proporcionar servicios básicos, percibidos unánimemente como una prioridad, pero en la mayoría de los casos el proceso no ha ido más lejos (ONU-Habitat, 2012).

Por otra parte, Briceño León (2007) sostiene que Latinoamérica es la región más violenta del mundo en relación con la criminalidad urbana. Esta violencia creciente ha implicado una transformación profunda en la vida cotidiana de las ciudades latinoamericanas, ya que esta impacta directa y diferenciadamente en la calidad de vida de hombres y mujeres (Falú, 2014). En las ciudades, la violencia - tanto la que se vive efectivamente como la que se percibe - constituye un tema emergente y complejo, que ocupa las agendas políticas y civiles. Según ONU-Habitat (2012), la violencia es la principal preocupación de los ciudadanos, por delante de la movilidad y del empleo. De hecho, las ciudades de América Latina y del Caribe están consideradas, en su conjunto, como las más peligrosas del planeta. Este aspecto de la vida en la ciudad tiende a convertirse en el principal criterio a la hora de elegir un lugar para vivir o para trabajar. No obstante, Falú (2014) aclara que estas violencias no son vividas ni sentidas de igual manera por toda la ciudadanía, no solo por sus condiciones socioeconómicas y las segregaciones en el territorio, sino también por la diversidad de los sujetos: no es igual ser mujer que hombre, ni joven que adulto mayor, menos aún pobre que rico.

La CEPAL (2016) señala que existen nuevos rostros de la desigualdad urbana: el envejecimiento, la vulnerabilidad de los jóvenes, los desafíos de la igualdad 
de género (aumento de la jefatura femenina), la migración intrarregional y el mayor reconocimiento de la diversidad y desigualdad étnica.

En este contexto de preocupaciones constantes, la ciudad se vuelve a configurar una y otra vez. En los últimos años la tendencia es a crear barrios cerrados, condominios urbanos, countries, urbanizaciones periurbanas y zonas residenciales monofuncionales. Estos tipos de vivienda responden a un modelo social particular que prioriza el bienestar y la comodidad individual sobre el interés colectivo o la búsqueda de cohesión social. En apariencia consolidan modelos de "vecindad" o "comunidad", pues sostienen redes y lazos intragrupales entre las personas que habitan esos espacios. Pero, realmente, terminan siendo guetos de clase y de raza. Según ONU-Habitat (2012), al mantener o reforzar la segregación espacial, estos modelos alimentan la reproducción de las desigualdades y contribuyen a la percepción de inseguridad.

En ese marco, la ciudad se divide de acuerdo a las clases sociales. Y la transitamos de manera que nos cruzamos y convivimos con aquellos que pertenecen a una misma clase social. El rostro de la pobreza no es visto por los ricos, quienes tampoco caminan territorios marginales. Hay una parte de las ciudades en las que solo circulan los pobres. Y son las personas en situación de pobreza quienes conviven con lo patológico del capitalismo y del consumismo: los basurales, los agrotóxicos, los deshechos, la falta de servicios. Las ciudades posmodernas (como Río de Janeiro, Buenos Aires o la Ciudad de México) cuentan con periferias marginales que sobreviven a lo residual del capitalismo y de la vida de consumo. A la inversa, los pobres transitan la ciudad de los ricos, pues son sus empleados, su servicio doméstico. Pero los ricos jamás pisan el suelo carente.

\section{¿QUIÉNES SON LOS OTROS Y LAS OTRAS?}

Siempre existe un otro o una otra. Alguien de quien debo diferenciarme, alejarme y aislarme. Alguien que me representa un peligro. Para los ricos, "el otro" son los pobres, los negros, los indígenas. Pero para los pobres también hay un "otro". Se constituyen diferentes "peligros" en torno a las personas pobres y surgen nuevos enfrentamientos: se diferencian de las poblaciones 
migrantes, se diferencian por género, por barrios, por territorios y hasta por gente bien y gente mal. Cruces y oposiciones que van surgiendo para diferenciarse, pues al final siempre está la existencia o, al menos, el imaginario de que alguien más puede convertirse en mi potencial enemigo.

En el caso de las mujeres, "el/la otrx" puede ser cualquiera y es por eso que espacios de disfrute como las plazas o parques pasan a ser lugares de miedo en determinadas horas. De esta forma, pierden "la vitalidad urbana potenciadora de las interrelaciones, de la socialización, del tejido social y del ejercicio de ciudadanía" (Falú, 2014, p. 18). Estas transformaciones y el abandono de los espacios públicos de las ciudades afectan en particular a las mujeres, que viven el temor independientemente de su condición social o su situación residencial, porque en ellas el miedo precede o acompaña a las violencias (Falú, 2014).Y, aunque tengan que recorrer territorios peligrosos o tramposos para su integridad, las mujeres salen igualmente a trabajar y los transitan. Entonces, para las mujeres, "el otro" es el varón patriarcal que puede ejercer sobre ellas violencia de algún tipo en las calles.

Asimismo, se puede explorar una serie de desventajas en el tránsito de las ciudades: por ejemplo, el transporte urbano que no solo se convierte en un lugar de riesgo donde ser acosada, sino que también se vuelve difícil de utilizar en caso de viajar con bebés, niños o discapacitados. Lo mismo sucede en el acceso a los espacios recreativos en ciertos horarios o, incluso, al centro de la ciudad cuando se trata de mujeres de barrios periféricos.

De acuerdo a los países o las regiones, el otro puede ser un chorro, un narco, un violador, un miembro de las maras, un naco, un bolita, un paragua, un favelero, un villero ${ }^{1} .$. Adquieren diversas nominaciones, pero la esencia es la misma. Ese otro representa a las clases sociales bajas, proviene de los sectores menos favorecidos, tiene un color de piel y unos rasgos físicos determinados que tienen poco que ver con la población occidental. Esos se convierten en los enemigos, pero también en los sospechosos: son a

1 Diferentes acepciones para denominar a los ladrones, los migrantes y los sujetos peligrosos de la sociedad. 
quienes se teme cuando circulan por la calle, a quienes la policía detiene por "portación de rostro", aquellos diferentes a los más favorecidos.

¿Y cómo sobrevivir frente a tanta discriminación cuando se está fuera del sistema, fuera de la urbanización, fuera de las marcas socialmente aceptables? Esos otros rodean la ciudad, no tienen derecho a ella, usurpan tierras, improvisan viviendas, son castigados material, social y culturalmente. Hay una anárquica superpoblación en los bordes de la ciudad y en sus alturas.

La periferia excluida, por su parte, anhela las casas en las que habitan los incluidos, sus autos, sus escuelas, su ropa... anhelan sentirse incluidos. Los excluidos se mueven fuera de todo marco, de toda red. No encuentran contención ni en el gobierno, ni en los educadores, ni en los vecinos, ni en sus territorios, que se han vuelto tierra de nadie, donde vale todo con el fin de sobrevivir (Bonavitta y Servín Valencia, 2012, p. 5)

Esos excluidos y excluidas trabajan en las casas de las élites:limpian sus viviendas, arreglan sus patios y espacios verdes, construyen sus hogares. Entonces, se enfrentan a diario a sus diferencias y marginalidades, a las desigualdades que ha traído consigo el capitalismo y las relaciones mercantilistas.

En ese marco, las "relaciones sociales establecidas al interior de la ciudad dejaron de ser relaciones estables, construidas históricamente, relaciones de proximidad al fin y al cabo" (Bonavitta y Servín Valencia, 2012, p. 6) y se convirtieron en relaciones de miedo, fundadas en una especie de terror paranoico a un otro construido por un Estado nación occidentalizado y racista, y sostenido diariamente por los medios de comunicación hegemónicos que repiten hasta el hartazgo microviolencias y microcolonialismos. La pobreza tiene género y tiene color en nuestras sociedades colonizadas.Y el contexto apunta a una lógica de consumo que implica constantemente el deseo de pertenecer. Pero ¿cómo pertenecer cuando material y simbólicamente han sido destinados a un espacio periférico, marginal y olvidado?

2 Así se denomina informalmente en Argentina a lo que motiva la detención: un rostro que no responde al occidentalismo. 


\section{CONSUMO DE VIDAS, DESEOS Y CREENCIAS}

Según Annunziata (2016),

el individuo contemporáneo no se concibe ya como perteneciente a una categoría o identificado con un grupo, se ha transformado en un individuo-historia, que necesita expresarse a sí mismo y ver reconocida su manera específica y singular de ser.Vivimos en una era de las singularidades. (p. 42)

Ya no se trata de ser iguales, como plantearon los ideales de la Revolución francesa, sino que se trata de una "igualdad en la singularidad" (Annunziata, 2016). Pero esta igualdad en la singularidad es tremendamente complicada en contextos de desigualdad social, económica y cultural.

En nuestras democracias las desigualdades crecen durante los últimos años de manera sorprendente [...]. Pero, paradójicamente, nuestra época presenta una suerte de "tolerancia implícita" frente a esta realidad: nunca se habló tanto de las desigualdades y al mismo tiempo nunca se hizo tan poco para reducirlas. Aunque se rechaza de manera global la forma actual de la sociedad tan desigual, pareciera que se aceptan los mecanismos que la producen (por ejemplo, las grandes desigualdades basadas en el mérito individual). (Annunziata, 2016, p. 51)

¿Cómo se puede hacer existir a la tan nombrada sociedad cuando la igualdad no es refundada y cuando el lazo social se desarma sin ánimos de reconstruirse?

Para Bauman (2005, p. 12), en nuestras sociedades contemporáneas atravesamos tiempos de vida líquida:

Esta vida se caracteriza por no mantener ningún rumbo determinado, puesto que se desarrolla en una sociedad que, en cuanto líquida, no mantiene mucho tiempo la misma forma. Y ello hace que nuestras vidas se definan por la precariedad y la incertidumbre constantes.

Entonces, sin lazo social y atravesando épocas de liquidez, nos vemos obligados a no ver lo esencial, a consumir sinsentidos y a quedar relegados del sistema, del Estado y de nosotros mismos.

La vida líquida es una vida devoradora. Asigna al mundo y a todos sus fragmentos animados e inanimados el papel de objetos de consumo: es decir, de objetos que pierden su utilidad (y, por consiguiente, su lustre, su atracción, su poder seductivo y su valor) en el transcurso mismo del acto de ser usados. 
Condiciona, además, el juicio y la evaluación de todos los fragmentos animados e inanimados del mundo ajustándolos al patrón de tales objetos de consumo. (Bauman, 2005, p. 12)

Para Bauman, esta liquidez anula cualquier posibilidad de utopía centrada en la sociedad. Y es que entonces nos preguntamos: ¿cómo pensar en una sociedad más justa y menos desigual en un marco donde el lema es el consumo y los deseos pasan a ser el acceso a las góndolas mercantiles?

Y así, se plantean ciudades preparadas para esos deseos voraces: cada vez más y más tiendas comerciales, con vidrieras llamativas, y una zona céntrica compuesta por las marcas europeas y norteamericanas de moda. ¿Quiénes, en América latina, acceden a esos productos? ¿Qué públicos pueden consumir los materiales importados? La ciudad está pensada para el consumo, pero el acceso real es de unos pocos. En una región con un $70 \%$ de población en situación de pobreza, ¿para quiénes se efectiviza la ciudad de los deseos? ¿Qué es lo que se vende? Se venden sueños — inalcanzables - para la mayoría y productos de consumo voraz para una minoría.

Desde el centro hacia la periferia, el consumo toma forma de pirámide clasista. Quien más afuera se ubique, peor se halla en la escala social y menos acceso tiene a los productos que ofrece el mercado. Conjuntamente, el sistema ofrece creencias y deseos a mansalva de ser quienes no somos, de alcanzar lo inalcanzable. Imágenes imposibles y accesos censurados configuran los espacios de una sociedad marginal, que habita territorios surcados por mensajes vacíos de contenido.

Según Martín Barbero (2012),

lo que ha convertido a algunas de nuestras ciudades en las más caóticas e inseguras del mundo no es solo el número de asesinatos o de atracos, sino la angustia cultural en que vive la mayoría de sus habitantes. Pues cuando la gente habita un lugar que siente extraño [...], cuando no se reconoce a sí misma como de ese lugar, entonces se siente insegura y esa inseguridad, aun a la gente más pacífica, la torna agresiva. (Barbero, 2012, p. 3)

La ciudadanía no se reconoce en los otros y las otras. Impera la voracidad y, tras ella, el miedo de no llegar a consumir. Cuando ese consumo se vuelve imposible, llega la soledad. El egoísmo y la segregación están ganándole 
la pulseada al contacto y a la comunidad. Las personas están aisladas de la ciudad, fuera del circuito mercantil, deseando sin concretar los sueños de consumo, portando un rostro no occidental... Los espacios se achican y las posibilidades se disuelven.

\section{A MODO DE CIERRE}

Los nadies: los hijos de nadie, los dueños de nada.

Los nadies: los ningunos, los ninguneados, corriendo la liebre, muriendo la vida, jodidos, rejodidos.

\section{Eduardo Galeano}

En las ciudades latinoamericanas conviven multiplicidad de géneros, etnias, culturas, sociedades; son espacios habitados por movimientos profundos y acciones de consumo. Por momentos, también se filtran las acciones de protesta, de rechazo a un sistema neoliberal y conservador que ha hecho de las ciudades lugares para el consumo de unos pocos y laberintos sin salida para quienes el sistema excluye, aísla y anula.

Son ciudades de premodernidad, modernidad y posmodernidad; donde circulan carretas guiadas por caballos, pero también automóviles automáticos, y coexisten modernos shoppings y centros comerciales junto con mercados ambulantes que permiten apenas la subsistencia de sus propietarios.

Son espacios habitados por triunfadores y excluidos del capitalismo: unos y otros en cada extremo de una ciudad que permite la coexistencia, pero no la equidad. Las mujeres y las sexualidades diversas son quienes más perciben los riesgos de las divisiones sexuales de las ciudades. Sus cuerpos no pueden transitar libremente, los temores se incrementan y la inseguridad acecha. El miedo a la oscuridad de la ciudad y a las lógicas machistas que comprenden al cuerpo de la mujer como un territorio de conquista monopolizan las lecturas que pueden hacerse sobre las ciudades libres de violencias. Para 
ellas, los hogares son peligrosos como espacios privados, pero también lo son los espacios semipúblicos y públicos del barrio, la comunidad y la ciudad. El patriarcado establece horarios de circulación para las mujeres, y la urbanística, espacios transitables y otros que no, de acuerdo con la disposición de las luces, la seguridad, las vías aptas para la circulación con carritos de bebé, etcétera.

Las exclusiones se multiplican y las posibilidades de ser parte del espacio urbano disminuyen. Se trata de ciudades atravesadas por lógicas patriarcales, racistas y clasistas, que dejan por fuera a quien no triunfa bajo lógicas capitalistas. Ciudades que se piensan y se construyen para poderosos y privilegiados, con diseños primermundistas y estructuras posmodernas. A sus márgenes, las construcciones improvisadas de ciudades que crecen hacia arriba, sin planificación alguna y reutilizando materiales. Son las villas de emergencia, las favelas, las ciudades perdidas, los barrios-ciudades, las colonias populares. Allí las lógicas desaparecen y la arquitectura se sostiene en bricolajes de materiales, formas y recursos. En esos contextos no triunfan los diseños estrella, sino la disponibilidad de recursos: desechos, regalos, préstamos, reciclados. Allí no hay ingenierías posibles, fuera de la necesidad extrema de crear techos para sobrevivir.

¿Para quiénes se diseñan esas ciudades? Para los privilegiados. Para los consumidores. Son ciudades construidas por varones (pues las obras más reconocidas y costosas pertenecen a ellos) para varones blancos, de clase media-alta y alta, burgueses, occidentales. La circulación segura se halla allí donde ellos viven, trabajan y consumen. El resto es anarquía, es el sálvese quien pueda, es la ciudad que a nadie importa, habitada por los y las "nadies". Allí conoces el olor del miedo y de la inseguridad, allí habita la precariedad sin sutilezas y todo se vuelve extraño y poco sutil a la mirada occidental, hegemónica y poco dominante. Tal como sucede en el mapa mundial, los efectos del neoliberalismo y la arquitectura del capitalismo se presentan ahí, en los espacios alejados del centro de poder. 


\section{REFERENCIAS}

Annunziata, R. (enero-abril del 2016). La democracia exigente. La teoría de la democracia de Pierre Rosanvallon. Andamios, 13(30), 39-62.

Bauman, Z. (2005). Vida líquida. Recuperado de https://circulosemiotico. files.wordpress.com/2012/10/vida-liquida-zygmunt-bauman.pdf.

Bonavitta, P., y Servín Valencia, M. (mayo del 2012). Las ciudades de los excluidos en una Latinoamérica posmoderna. Kairos. Revista de Temas Sociales, 16(29), 5-10.

Briceño León, R. (2007). Sociología de la violencia en América Latina. Ecuador: Flacso.

Comisión Económica para América Latina y el Caribe. (2016). Los retos para las ciudades en América Latina y el Caribe y el plan de acción regional post-2016. Hacia la ciudad del futuro. Recuperado de https:// www.cepal.org/sites/default/files/events/files/03_lucy_winchester_-_ la_ciudad_del_futuro.pdf

Comisión Económica para América Latina y el Caribe. (enero del 2013). Panorama social de América Latina 2012. Recuperado de https:// repositorio.cepal.org/handle/11362/1247

Falú, A. (diciembre del 2014). El derecho de las mujeres a la ciudad. Espacios públicos sin discriminaciones y violencias. Vivienda y Ciudad, (1), 10-28.

Martín Barbero, J. (2012). La ciudad: entre medios y miedos. Revista Universitaria, (9). Recuperado de http://educa.upnvirtual.edu.mx/ educapdf/rev9/martin-009.pdf

Programa de las Naciones Unidas para los Asentamientos Humanos. (2012). Estado de las ciudades de América Latina y el Caribe 2012. Rumbo a una nueva transición urbana. Recuperado de http://estaticog1.globo. com/2012/08/21/Estado-de-las-Ciudades-de-America-Latina-y-elCaribe-2012.pdf 
